\title{
PRESENTACIÓN DOSSIER "TUKMA: PAISAJES, TEXTOS, IMÁGENES Y MATERIALIDADES (SIGLOS XVI-XVIII)"
}

\author{
TUKMA: LANDSCAPES, TEXTS, IMAGES AND MATERIALITY \\ (16TH-18TH CENTURIES)
}

En 1542 el gobernador de Perú, Cristóbal Vaca de Castro, informaba al rey que entre la provincia de Chile y el rio grande que llaman de La Plata, hay una provincia que se llama Tucma (...) que dicen que es muy poblada y rica. Las noticias de una tierra rica y promisoria, gobernada por un cacique poderoso, convirtieron a Tukma en una región tan desconocida como atrayente para el proceso de conquista que se iniciaba desde el Cuzco hacia el sur. En manos de la administración colonial la voz prehispánica Tukma fue apropiada para designar una gobernación que, desde las altas cumbres de la cordillera, incluía las punas y valles de los diaguitas hasta las yungas del oriente y las sierras de los comechingones.

Mediante el diálogo interdisciplinario y la multiplicidad de fuentes (textuales, cartográficas, etnográficas y materiales) convocamos al simposio "TUKMA: Paisajes, textos, imágenes y materialidades (siglos XVI-XVIII)" en el marco del XX Congreso Nacional de Arqueología Argentina, realizado en la ciudad de Córdoba en julio de 2019. La convocatoria abierta a investigadores de Arqueología, Historia y Antropología atrajo una diversidad de casos de estudio y metodologías de trabajo que quedan de manifiesto en los proyectos presentados.

Nuestro objetivo era dar un nuevo sentido a la palabra Tukma en el contexto de los debates pertinentes a paisajes, discursos y poblaciones indígenas en la heterogénea sociedad colonial. Un punto de partida para construir un diálogo entre arqueología e historia en el área andina se encuentra en una revisión de categorías teóricas, perspectivas y miradas que, desde la palabra escrita y los restos arqueológicos, abordan la conformación de Tukma como parte de un espacio andino colonial.

Desde la cultura material, la memoria, la palabra escrita y la oralidad buscamos reconstruir un pasado tamizado por la posesión desigual de la escritura. Por esto, no corresponde un estudio arqueológico solo ante la falta de documentos escritos, sino que es posible -y hasta necesarioanalizar las relaciones sociales desde un lugar diferente, el de los objetos y su contexto, aun cuando se disponga de información histórica.

En los últimos años el concepto de materialidad, definida por una relación integrada de la vida material, la experiencia de los actores y los discursos que construyen y reproducen significados sociales brinda un espacio promisorio para plantear estudios interdisciplinarios. Prácticas y representaciones, materialidad y significado se entienden en permanente interacción, conflicto y asimetría entre el poder de la metrópoli, las autoridades locales y las sociedades andinas con sus propias dinámicas, tensiones y conflictos.

Los doce trabajos que integran este dossier fueron presentados en el simposio Tukma y son aportes de investigadores e investigadoras de las Universidades Nacionales de Salta, Tucumán, Catamarca, Córdoba, Buenos Aires y de la Universitat Autònoma de Barcelona, España. Destacamos la participación de una nueva generación de estudiantes e investigadores interesados en el Tucumán de los siglos XVI-XVIII y el diálogo entre disciplinas y fuentes que se expresa en los artículos.

Dos de ellos refieren a las provincias incas de Chicoana y Quiri Quiri, las que fueran mencionadas en las fuentes coloniales del siglo XVI y XVII para el sur del Tawantinsuyu. Ambos artículos integran fuentes escritas y la información brindada por la arqueología. El primero, "Sobre la provincia Inca de Chicoana, reflexiones y discusiones desde el cruce de fuentes", de María Cecilia Castellanos, aborda la conformación de la unidad administrativa de Chicoana en el marco del Estado inca. Aquí se discute su demarcación física, siguiendo la propuesta de Mulvany (1998), y se busca identificar los indicadores para entender dicha unidad. Se plantea que esta provincia comprendía un escenario configurado a partir de un espacio agrícola y minero asociado a la producción, incluyendo 
poblaciones y espacios de quebradas y valles altos del Calchaquí, además de otros paisajes asociados al valle de Lerma y, quizás, la puna.

El trabajo de Laura Quiroga "Quiri Quiri: toponimia, memoria y geografía de la exacción inca y colonial temprano en los valles de Londres y Pacinas (siglos XV-XVII)", aporta valiosa información acerca de una de las provincias incaicas que ha sido poco abordada desde los estudios etnohistóricos. Las fuentes escritas, la información arqueológica y el estudio de la toponimia permiten a la autora proponer que los topónimos extraídos de la documentación del siglo XVI, constituyen una red de relaciones espaciales que reinterpreta las marcas del pasado. A partir de la lectura crítica de las fuentes escritas se identifican en el trabajo ciertos sesgos desde la lectura colonial. Uno de ellos, sumamente interesante, sostiene que, inicialmente, la mirada española respecto de esta provincia aludía a aquello que pudiera servir a la conformación de un paisaje minero -de origen prehispánico- en la nueva contingencia política.

El dossier presenta un conjunto de trabajos que reflexionan concerniente al problema de las transformaciones que supone el orden colonial para poblaciones indígenas considerando asentamientos, instalaciones coloniales, procesos de trabajo de la población indígena y evangelización.

El trabajo de Lucas Borrastero, "Participación indígena en las actividades productivas del espacio rural de Córdoba. Revisión del pueblo de encomienda del Quilpo a fines del siglo XVI", analiza el trabajo de los indios de encomienda de la región de Quilpo, serranías de Córdoba, en relación con la producción de hilados y tejidos y actividades agrícolas y ganaderas. En este sentido, nos presenta una relación entre la forma de producción prehispánica y la inserción en el sistema económico colonial producto de un proceso al que el autor denomina de hispanización.

Siguiendo con el ámbito rural, el trabajo de Ignacio Díaz, Marcos Quesada y Félix Retamero, "Espacios campesinos indígenas y estancias coloniales: el caso de Santa Cruz (Valle Viejo, Catamarca, Argentina). Siglos XVI-XVIII. Primeros resultados", analiza la conformación de la estancia colonial como forma productiva desde la perspectiva de los sistemas de riego prehispánico como base para el desarrollo de paisajes campesinos y agrarios entre los siglos XVI y
XVIII. Su perspectiva de análisis integra y compara espacios de colonización castellana en el sur de España, Canarias y el Tucumán.

El trabajo de Antonela Nagel y Rodolfo Cruz, "La Merced de Opca. Ocupación y disputas por la tierra en la sierra de 'El Alto-Ancasti' durante los siglos XVII-XVIII (Catamarca, Argentina)", aborda un problema relevante del paisaje y territorio analizando no solo las descripciones materiales de la conformación de estancias y mercedes, sino también el proceso de mensura y amojonamiento, aspecto referido a la noción de propiedad.

Pablo Mignone plantea un análisis cartográfico y de georreferenciación de dos instalaciones coloniales recurrentes para la ocupación del espacio, entendidas como herramientas materiales del poder colonial: la reducción y el fuerte. En este caso, "La materialidad de la dominación: mapas manuscritos, fuertes y reducciones indígenas en la quebrada de Escoipe (siglos XV-XVIII), valle de Lerma, Salta-Argentina".

En "Conflictos en las encomiendas y reducciones de Pulares y Guachipas de la jurisdicción de Salta: la participación indígena en el sistema judicial (fines del siglo XVII)", Facundo Rueda aborda un caso de análisis que aporta al conocimiento acerca de la participación de los indígenas en los tribunales frente al orden colonial. En este caso, el autor demuestra la relación estrecha entre los intereses del estamento encomendero y la participación de sacerdotes en el desarrollo del juicio.

Marisol García presenta un trabajo basado en fuentes judiciales donde los indígenas, por medio de su cacique, presentan demandas por los traslados a los que fueron sometidos por los encomenderos. Como parte del desarrollo del juicio se describen las instalaciones productivas y residenciales que incluía un pueblo de indios: "La dimensión material de un pueblo de indios: la estancia de Guaco a través de fuentes judiciales (La Rioja, 1685)".

El aporte de Telma Chaile aborda la conformación espacial y material del espacio desde la perspectiva del desarrollo e instalación de los ámbitos devocionales marianos. Desde un análisis comparativo reconstruye la "Ocupación espacial y devoción en las configuraciones de cultos a la Virgen del Valle y Virgen de Belén en Catamarca (mediados del siglo XVII-siglo XVIII)". 
María Josefina Pérez Pieroni y Marco Giusta nos presentan el artículo "Materiales cerámicos coloniales en Antiguyoc (puna de Jujuy, Argentina): aproximación a su producción, circulación y uso". En él abordan el estudio de un conjunto cerámico del sitio Antiguyoc, un asentamiento de la puna jujeña que funcionó como asiento minero y viceparroquia hacia finales del siglo XVIII. El diálogo entre las fuentes escritas, la evidencia material y los datos etnográficos disponibles para la zona, permitió a los autores generar información relativa a prácticas cotidianas desarrolladas en el asentamiento y aportar nuevos datos de las tradiciones alfareras locales bajo un contexto de orden colonial.

Otro de los temas abordados en este número refiere al estudio del ambiente y el entorno en contextos coloniales. El trabajo "Aproximaciones climáticas en la antigua ciudad de Ibatín, siglos XVI-XVII, Tucumán, Argentina", de Florencia Borsella y Alexis Ernesto Weber, nos presenta una mirada a las condiciones climáticas en Ibatín, primera ciudad fundada en el siglo XVI en el piedemonte tucumano. A partir de información recuperada de fuentes escritas tempranas y estudios geológicos, los autores reconocen eventos climáticos que les permiten caracterizar las condiciones ambientales y del entorno donde se emplazaba originalmente la antigua ciudad. Agregan también información que da cuenta de la introducción de nuevas especies vegetales y animales, y de las modificaciones que pudieron generar las actividades antrópicas producidas a partir de las primeras fundaciones de asentamientos españoles como Ibatín.

En "Acerca de animales, plantas y el procesamiento de fibras en el vocabulario Lule-Tonocoté del padre Machoni (1732). Buscando colores en un espacio misional de frontera, siglo XVIII, Chaco salteño", Mabel Mamani trabaja con el escrito Arte y Vocabulario de la Lengua Lule y Tonocoté, del padre Antonio Machoni de Cerdeña, miembro de la Compañía de Jesús, el que contiene información referente a dos reducciones misionales del río Salado durante el siglo XVIII. En el artículo, la autora identifica recursos animales y vegetales mencionados en este interesante escrito y nos brinda información del espacio, los aspectos de la vida cotidiana, saberes y prácticas artesanales indígenas vinculadas al tejido. Desde esta mirada, se trabaja también los colores en vinculación con la práctica del tejido y con el conocimiento en torno a la naturaleza.

Finalmente, queremos expresar nuestro agradecimiento a las personas que hicieron posible la publicación de los resultados de este simposio: al Director y Editores de Diálogo Andino, a los evaluadores y evaluadoras que han enriquecido cada uno de los artículos y a las autoras y autores por sumarse a la propuesta. 